\title{
Difusão lexical em sintaxe
}

\author{
MARIA CECÍLIA MOLLICA \\ Universidade Federal do Rio de Janeiro
}

\section{Abstract}

This paper discusses the possibility of the application of the Lexical Diffussion model to a syntactic phenomenon. It shows the importance of lexical parameters, Formality and Frequency, as factors of implementation of "Queismo" and "Dequeísmo" in Portuguese. Statistical results demonstrate that the two processes are only apparently opposite in the system and that they are, in fact, closely related, so that we can consider them as the same variatrion focus in the language. 


\section{OBJETIVOS 1}

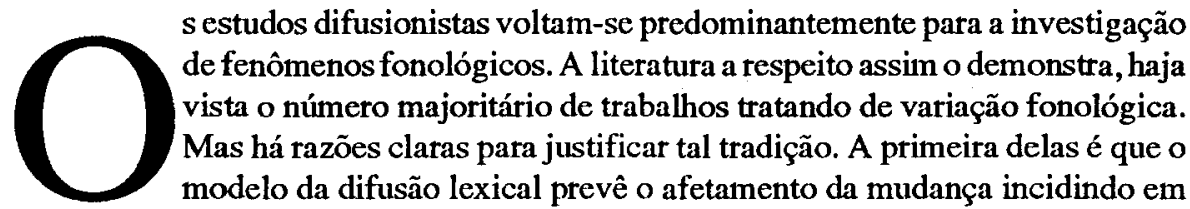
itens lexicais, e a variação ou mudança em outros niveis da língua afeta constituintes, unidades maiores, nem sempre claramente definidos. A proposta considera o léxico, implicando, conseqüentemente, itens, isto é, a unidade vocabular.

Este artigo discute a viabilidade de aplicação da abordagem difusionista $\mathrm{em}$ fenômeno sintático e a importância da investigação de parâmetros lexicais, como indícios da relação entre a natureza de uma inovação lingüística e seu início e/ou estágio de implementação no sistema. Apresento, inicialmente, estatísticas que computam todo o universo lexical e, posteriormente, cálculos que levam em conta tão somente a interseção lexical entre os corpora analisados.

\section{QUESTÕES E OBJETO DE ANÁLISE}

Na pesquisa sobre queísmo e dequeísmo, que constitui o foco de atenção em tese de doutorado (cf. Mollica, 1989), concluí que as variantes ' $\odot$ que' e 'de que' se alternam em fronteiras sintagmáticas enquanto opções preposicionais em conexões inter-sentenciais. Eminentemente sintáticos em sua natureza, esses processos incidem sobre o sistema preposicional da língua, configurando-se como movimentos contrários, inversamente proporcionais, de cancelamento e inserção do nexo preposicional 'de' diante do conector 'que' em certos intervalos sintáticos.

No caso do queísmo, os contextos favorecedores são sentenças subordinadas objetivas indiretas, completivas nominais ou adjetivas em que o verbo da cláusula requer preposição. No caso do dequeísmo, os campos sintáticos propícios são orações subordinadas substantivas subjetivas, objetivas diretas, apositivas, adjetivas em que não haja necessidade de preposições, ou locuções em que 'que' esteja presente.

No trabalho mencionado, concluí que ambos os processos constituem um único foco de variação, configurando-se como impulsos produtivos no sistema do português desde os seus primórdios. Demonstrei que tais forças se acham razoavelmente controladas por fatores extra e intra-sistêmicos, dentre os quais os que dizem respeito a características do léxico envolvido. 
A variação nas fronteiras queístas está fortemente implementada no português, enquanto em fronteiras dequeístas ela se comporta de maneira inversa: é relativamente recente no sistema, a variante 'de que' tem seu emprego motivado por mecanismos de hipercorreção e, como tal, supostamente prestigiado, embora seu emprego constitua um desvio da norma gramatical. Assim, o queísmo tende a ser usado por indivíduos de escolarização baixa e em contexto de formalidade também baixa; já o dequeismo tende a ser empregado por indivíduos mais escolarizados e em situações de alto grau de tensão e formalidade discursiva. Essas são conclusões extraídas de análise multivariacional quantitativa. Uma investigação voltada para o léxico envolvido entre estruturas queistas e dequeístas a ela se actescentou, reforçando-lhe os achados (cf. Mollica, op. cit.).

\section{TRATAMENTO DIFUSIONISTA}

Utilizei algumas ferramentas da análise difusionista com a finalidade de corroborar os resultados mencionados. Trabalhei com vários corpora de dados: a amostra Censo e alguns inquéritos do acervo NURC/RIO DID constituíram o conjunto de fala semi-espontânea, de discurso não planejado, em contexto informal; gravações avulsas de programas de entrevistas ao vivo na Mídia bem como o acervo NURC/RIO EF compuseram o material lingüístico avaliado como de discurso planejado em contexto formal. O detalhamento técnico das características dessas amostras pode ser encontrado em Castilho e Preti (1986), Naro (1986) e Mollica (op. cit.).

Para a análise do léxico envolvido, lancei mão de índice de freqüência e de grau de formalidade dos itens (cf. Phillips, $1984 \mathrm{c}$ Oliveira, 1991) potencialmente afetados pelo queísmo, que se comportam de modo a poder-se apontar direções diametralmente opostas aos dois processos e a sustentar as seguintes premissas: a) quanto mais implementada e desprestigiada é uma estrutura, mais ela tende a incidir em itens de alta freqüência e de baixa formalidade; b) quanto mais rara e mais prestigiada é a estrutura, mais ela tende a ocorrer em itens menos freqüentes e mais formais. Esses princípios se evidenciam numericamente, conforme comprova a Tab. 1. No caso do parámetros Freqüência, nela estão calculados todos os itens potencialmente afetados pelos processos em questão em todas as amostras rastreadas. Já para o parâmetro Formalidade, foram levados em conta somente os itens que pudessem estabelecer reciprocamente a relação | +/- formal|. Nesta Tab., portanto, o léxico foi considerado independentemente das amostras.

\section{TABELA 1}

Relação entre queismo e dequeísmo e freqüência e formalidade lexical

\begin{tabular}{l|c|c|c|c|c}
\hline \multirow{4}{*}{} & \multicolumn{3}{|c|}{ Frequência } & \multicolumn{2}{c}{ Formalidade } \\
\cline { 2 - 6 } QUEISMO & Baixa & \multicolumn{1}{c|}{ Média } & Alta & + Formal & - Formal \\
DEQUEISMO & $39 / 114=34 \%$ & $153 / 309=49 \%$ & $341 / 485=70 \%$ & $6 / 18=33 \%$ & $105 / 15169 \%$ \\
\hline
\end{tabular}

De acordo com a Tab, 1, há uma relação clara entre índice de ocotrência e grau de . afetamento dos processos queísta e dequeísta. Os itens de baixa ocorrência são menos 
afetados pelo queísmo. A taxa de afetamento do processo aumenta, na medida em que se eleva o númeto de ocortências de um certo item. Por outro lado, os itens menos freqüentes são justamente os mais atingidos pelo dequeísmo. $O$ percentual de afetamento cai quase a $\varnothing \mathrm{em}$ itens que ocorrem mais. Esse fato evidencia-se também no espanhol, tal como mostrado por Bentivoglio y D'Introno (1977), o que, segundo os autores, constitui mais suporte a favor da tese da hipercorreção.

Diametralmente opostos, esses resultados permitem entrever uma "lógica" lexical no fato de certos itens serem afetados e outros não e, indiretamente, podem revelar o caminho que queísmo e dequeísmo têm percorrido para se implantar no sistema. Ora, se queísmo implica o emprego da variante não standard, menos prestigiada, é de se supor que 'ø que' se processe em universo vocabular 'mais comum', 'mais corriqueiro', portanto 'mais freqüente'. Se o dequeísmo pressupõe o emprego da variante standard, mais prestigiada, a estrutura 'de que' deve acompanhar itens menos comuns e, conseqüientemente, menos freqüentes.

Há de se destacar a complementaridade desses resultados com aqueles relativos à formalidade do item, cuja estreita interação com Freqüência já era esperada. O percentual de afetamento de queísmo é bem alto quando associado a itens |-formal| $e$ se comparado ao dos itens classificados como $1+$ formal|. Por outro lado, o índice de afetamento do dequeísmo é tanto mais alto quanto mais alto também é o grau de formalidade do item potencialmente afetado. Assim, também em direções opostas, o 'grau de formalidade lexical' regula o léxico envolvido para queísmo e dequeísmo: para queísmo, nos itens de traço |- formal|; para dequeísmo, nos itens de traço |+ formal|. A estrutura queísta, enquanto variante desprestigiada, tende a afetar itens de traço|-formal|; a estrutura dequeista, enquanto variante "julgada prestigiada", tende a afetar os itens de traço $\mid+$ formal|.

Esse panorama de resultados para o parâmetro Formalidade se confirma de forma bastante positiva quando se levam em conta: a) as amostras em separado, de acordo com as características já mencionadas; b) apenas a interseção lexical, isto é, aos itens que ocortem em todas as amostras, como na Tab. 2.

\section{TABELA 2}

Interseção lexical levando-se em conta todas as amostras

\begin{tabular}{c|c|c|c}
\hline \multicolumn{2}{c|}{ Queismo } & \multicolumn{2}{c}{ Dequeismo } \\
\hline+ formal & - formal & + formal & - formal \\
$30 / 41=73 \%$ & $175 / 205=85 \%$ & $2 / 194=1 \%$ & $0 / 1365=0 \%$ \\
\hline
\end{tabular}

Já na Tab. 3, estão mostrados os resultados considerando-se a oposição|+/-formal|, as amostras de per si e o léxico em interseção. 


\section{TABELA 3}

Amostras cruzadas segundo grau de formalidade das entrevistas - itens em comum

I- - - formal

\begin{tabular}{c|c|c|c}
\hline \multicolumn{2}{c|}{ Censo/DID } & \multicolumn{2}{c}{ Gravacões Avulsas / EF } \\
\hline Queismo & Dequeísmo & Queísmo & Dequeísmo \\
\hline CENSO & & Gr. Av. & \\
$88 / 92=96 \%$ & $2 / 1457=0 \%$ & $14 / 34=41 \%$ & $34 / 452=8 \%$ \\
DID & & EF & \\
$52 / 101=51 \%$ & $0 / 570=0 \%$ & $11 / 19=58 \%$ & $0 / 117=0 \%$ \\
TOTAL: & & TOTAL: & \\
$140 / 193=73 \%$ & $2 / 2027=0 \%$ & $25 / 53=47 \%$ & $34 / 569=6 \%$ \\
\hline
\end{tabular}

Novamente observa-se a seguinte relação: queísmo está para |-formalidade| assim como dequeísmo está para |+ formalidade|. Essa relação se emparelha àquela segundo a qual um processo mais avançado, que pressupõe variante desprestigiada, deva ocorrer em contextos menos formais, enquanto processos apenas iniciantes, com características de hipercorreção, devam ocorrer em contextos mais formais.

Fica assim atestado que o parâmetro lexical Formalidade constitui um agente regulador sobre o grau de afetamento de queísmo e dequeísmo, assim como é o parâmetro Frequiência. Como mecanismo de desvio padrão, já altamente implementado no português, numa taxa que varia entre $50 \%$ e $80 \%$ a depender do tipo de amostra, a estrutura queista afeta itens 'mais usuais' e 'menos formais'. Como mecanismo de hipercorreção e como processo apenas recente no idioma, por outro lado, a estrutura dequeista é considerada como prestigiada, e nada mais coerente do que se pensar que ela venha a acompanhar itens lexicais 'menos comuns', 'mais formais', que substituem termos mais corriqueiros.

\section{ALGUMAS PONDERAÇÕES}

Após sumário da abordagem difusionista com dados queistas e dequeístas, cabe levantar dois pontos. Essa análise complementa a que examina contextos sistêmicos (cf. Mollica op. cit.) sob o prisma variacionista. Grau de formalidade é uma variável importante tantoem relação ao do contexto de fala em que ocorrem quésmo e dequeísmo, quanto em relação ao item lexical potencialmente afetado por queísmo e dequeísmo.

Essa análise, no entanto, tem restrições. Dela só se pode inferir indiretamente a maneira pela qual os dois processos vêm se infiltrando no português. Mas nada fica completamente assegurado, pois os parâmetros não foram analisados do ponto de vista da variável Tempo, embora os acervos do NURC datem da década de 70 e os demais da década de 80 . O controle da variável Tempo, quando considerado grosso modo nas duas décadas, não oferece resultados consistentes. Estou realizando, ${ }^{2}$ como continuidade a essa pesquisa, o acompanhamento regular e sistemático da forma como o fenômeno vem se comportando no português de hoje e em toda a sua história, de modo a poder lançar luzes quanto à difusão de queísmo e dequeísmo ao longo de todo o percurso da diactonia da nossa língua. 


\section{NOTAS:}

${ }^{1}$ Esse texto é uma versão revista e ampliada da comunicação apresentada na mesa-redonda sobre Difusão Lexical, durante os trabalhos do GT de Sociolingüistica, na V Reunião da ANPOLL, Recife, 1990.

${ }^{2}$ Esse trabalho vem sendo desenvolvido conjuntamente com a bolsista Simone Correia Silva, que, desde agosto de 1990, vem recebendo auxilio do CNPq na modalidade de IC.

\section{REFERÊNCIAS BIBLIOGRÁFICAS}

BENTIVOGLIO, Paola, D'INTRONO, Francesco. Análisis sociolingüistico del dequeismo en el habla de Caracas. Boletin de la academia puertorriqueña de la língua española, v. 1, p. 58-81, 1977.

CASTILHO, Ataliba, PRETI, Dino. (orgs.) A linguagem falada culta na cidade de São Paulo. São Paulo: T.A. Queiroz, 1986. v. 1.

MOLLICA, Maria Cecília. Queísmo e dequeísmo no português do Brasil. Rio de Janeiro: UFRJ, 1989.306 p. Tese (Doutorado). Faculdade de Letras, Universidade Federal do Rio de Janeiro.

NARO, Anthony J. Relatório final de pesquisa: subsídios sociolingüísticos do Projeto Censo à Educação. Rio de Janeiro: UFRJ, 1986. 2v.

OLIVEIRA, Marco A. de. The neogrammarian controversy revisited. International journal of the sociology of language, Berlin, v. 89, p. 93-105, 1991.

PHILLIPS, B. S. Word frequency and the actuation of sound change. Language, v. 60 , n. 2 , p. $320-342$, jun., 1984. 